\title{
Integration by identification of indicators
}

\author{
V. Giannini ${ }^{1,2}$ and C. Giupponi ${ }^{1,2}$ \\ ${ }^{1} \mathrm{Ca}$ ' Foscari University of Venice, Italy \\ ${ }^{2}$ Fondazione Eni Enrico Mattei, Venice, Italy
}

\begin{abstract}
The objective of the BRAHMATWINN research component described in this chapter is to develop integrated indicators with relevance to Integrated Water Resources Management (IWRM) and climate change for the Upper Danube and the Upper Brahmaputra River Basins (UDRB and UBRB), and to foster the integration process amongst the different research activities of the project. Such integrated indicators aim at providing stakeholders, NGOs and GOs with an overview of the present state and trends of the river basins water resources, and at quantifying the impacts of possible scenarios and responses to driving forces, as well as pressures from likely climate change. In the process the relevant indicators have been identified by research partners to model and monitor issues relevant for IWRM in the case study areas. The selected indicators have been validated with the information gathered through the NetSyMoD approach (Giupponi et al., 2008) in workshops with local actors. In this way a strong link between the main issues affecting the basins as perceived by local actors and the BRAHMATWINN activities has been created, thus fostering integration between research outcomes and local needs.
\end{abstract}

\section{Introduction}

This chapter describes the development of a set of integrated indicators to support IWRM, and to cover the environmental, social, economic, and governance spheres relevant for the project study areas. Indicators are used to simplify, quantify, communicate, and create order with complex data. They convey information that is synthesised, and that can therefore help to reveal complex phenomena. As indicators allow us to measure phenomena or monitor changes and progresses, they thus enable the establishment of a common ground, to compare different areas and situations, and draw conclusions.

A set of indicators that are able to describe in a concise but accurate manner the key environmental, social, economic, and governance aspects related to climate change impacts and IWRM in both Europe and Asia is needed to support the processes of IWRM strategies development, by providing countries with clear priorities. The literature on the selection of indicators is rich, and several international institutions active in various fields have proposed their own core sets of indicators that can be a useful starting point. These include, for instance:

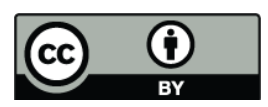

Correspondence to: V. Giannini (valentina.giannini@feem.it)
- the EEA core set of indicators (EEA, 2005);

- the Indicators of Sustainable Development (DESA/DSD, 2001);

- OECD core set of indicators (OECD, 2007);

- The core sets of indicators for Eastern European, Caucasus and Central Asia (EECCA) by UNECE (www.unece.org);

- A core set of European Health Environmental indicators (www.euro.who.int).

\section{Role within the integrated project}

The creation of the Integrated Indicator Table (IIT), which will be described in this chapter and of its framework, should simplify exploring the data provided by the different models used in the BRAHMATWINN project. The IIT will also help researchers to compare and communicate the project's results in a concise but meaningful manner. The hierarchical structure of the IIT allows for flexibility, having different measures according to the different case study areas, and disciplines involved. The IIT is useful to integrate the results of research coming from the different disciplines represented, however, as any classification has some limitations and rigidity. 


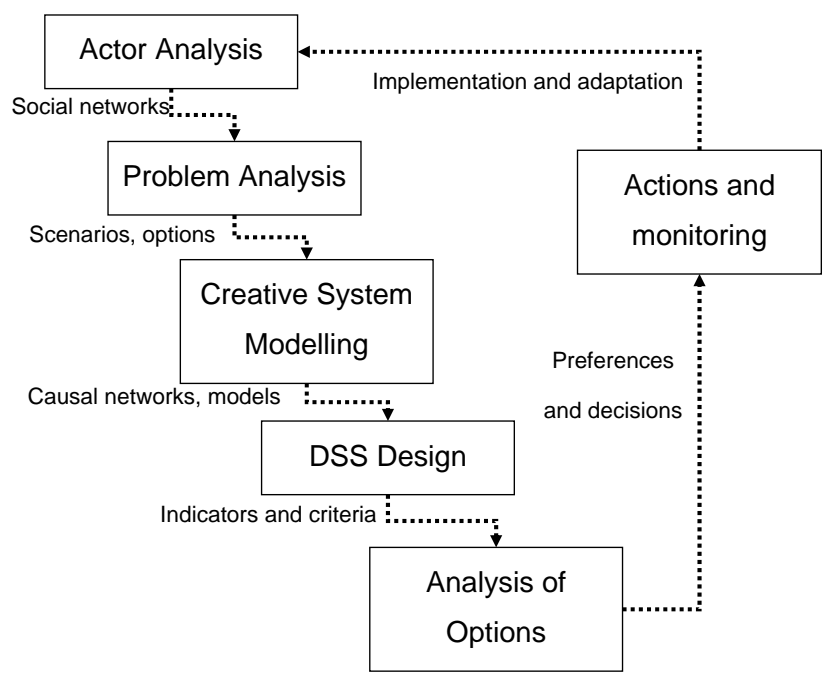

Figure 1. The NetSyMoD approach for participatory modelling and decision making (source: Giupponi et al., 2008).

\section{Scientific methods applied}

\subsection{NetSyMoD}

The NetSyMoD approach relies on the DPSIR (Driving Forces - Pressures - State - Impacts - Responses) framework (EEA, 1999) for problem conceptualisation and indicator selection. There are six steps envisaged within this methodology (Giupponi et al., 2008): two phases in particular have been used to build the Integrated Indicator Table (IIT), and are discussed here: (1) Problem Analysis, and (2) Creative System Modelling (see Fig. 1).

In the Problem Analysis phase the opinions of Local Actors (LA) are elicited to describe the problem, taking into account all possible aspects. Creative System Modelling (CSM) techniques facilitate the process of participatory modelling and elicitation of knowledge and preferences from actors, thus build a common understanding of the problem framed in the DPSIR framework.

The key actors identified in the first NetSyMoD phase Actor Analysis - are now involved in the development of a shared vision of the human-environmental system. They may be involved in various ways, typically through a participatory workshop, during which creative thinking and cognitive mapping techniques are used to develop a shared model of the problem. The CSM workshop can have two main aims, depending on the case at hand:

1. building a shared model of the problem, based on causeeffect chains and using the DPSIR conceptual model, and

2. developing shared scenarios, investigating the potential evolutions of the system over time, or under different policies (this is the objective of the CSM workshops organised for the activities described in Chapter 8).

\subsection{Workshops}

The list of concepts collected during the CSM workshops carried out in Assam (April 2007), Bhutan (October 2007), Austria (October 2008), Nepal (November 2008) and Austria-Germany (February 2009) have been included in the list of indicators and responses. Four fields in the Integrated Indicator Table (IIT) list the issues and responses elicited from local actors in each case study area, i.e. we allocated within the below described framework issues and responses arisen during the CSM workshops, establishing a two way relationship at the Sub-domain level. The framework of the IIT is shown in Table 1, while an extract of it is shown in Table 2.

The CSM workshops allowed to elicit from local actors involved ideas and concepts related to the main issues affecting the project case study areas, and existing or needed response strategies to cope with them. The issues/responses identified can be expressed as indicators and complete the list of indicators identified by researchers. The scope is, in fact, to compare the quantitative information provided by research partners with the qualitative information provided by local actors during the workshops, and carry out a validation process. This process makes sure that relevant indicators describing and characterising the local context are included in the set (see Table 2).

The identification of quantifiable indicators to monitor the evolution of the different components of the causal loop diagrams is also necessary to develop future plausible scenarios for the case study areas, which will in turn enable the assessment of existing and potential responses in the years to come.

\subsection{The structure of the Integrated Indicator Table}

The structure of the Integrated Indicator Table (IIT) was defined in agreement with the BRAHMATWINN research partners. The set of integrated indicators is designed as a multilevel list, a tool for integrated assessment. The structure in which the indicators are organised is composed of four categories: Themes - Domains - Sub-domains - Indicators (see Table 1).

The Themes aim at characterising a sustainability framework, and are:

- Environmental describes the state of the Natural Environment.

- Social guarantees that the Human Dimension is described.

- Economic describes the human economic activities. 
Table 1. Integrated Indicator Table (Themes, Domains, Sub-domains) and allocation to DPSIR scheme.

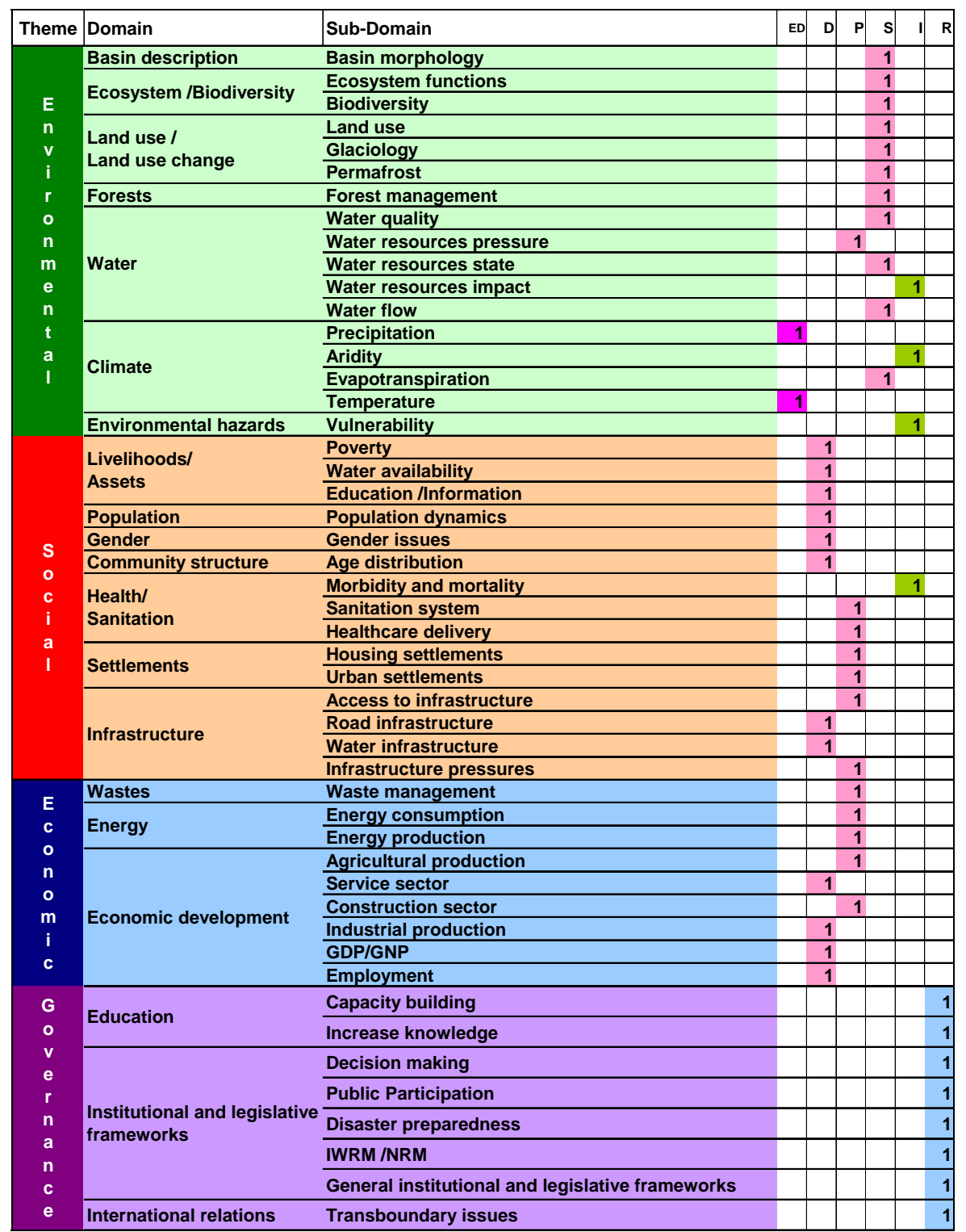

- Governance describes the legislative and institutional frameworks, including the degree of public participation, education and awareness of a population.

Indicators provide information about complex, typical or critical processes in social-ecological systems, and simplify communication about the issues addressed. Research activities within the BRAHMATWINN project are many and varied, they fall within different disciplines, and they make use of various models and assessment frameworks. As a consequence, a significant number of indicators and data sets are required to populate the different models and approaches. To facilitate the identification of integrated IWRM indicators and of intra-disciplinary linkages, within this project we have adopted the terminology of domain to identify a particular Environmental, Social, Economic or Governance issue (e.g. Land-use/Land-cover change, Environmental Hazards, Livelihoods/Assets, Health/Sanitation, Energy, Economic development, Education, Institutional and legislative frameworks...). Sub-domains have also been defined, for the identification of more specific categories of issues addressed by groups of - site specific - detailed indicators. For instance the domain Climate could be subdivided into four sub-domains: Precipitation, Temperature, Aridity and Evapotranspiration, each of them quantified by one or more indicator. 
Table 2. IIT section: Example of matching local actors' opinions with BRAHMATWINN researchers' indicators.

\begin{tabular}{|c|c|c|c|c|}
\hline Theme & Domain & $\begin{array}{l}\text { RESEARCHERS' } \\
\text { INDICATOR }\end{array}$ & Sub-Domain & $\begin{array}{l}\text { LOCAL ACTORS' } \\
\text { ISSUE }\end{array}$ \\
\hline \multirow{6}{*}{ E } & \multirow{19}{*}{ Water } & $\begin{array}{l}\text { Number of water extraction \& } \\
\text { discharge }\end{array}$ & \multirow{3}{*}{ Water quality } & Effluents treatment \\
\hline & & Water quality & & Pollution \\
\hline & & Contamination of ground water & & \\
\hline & & Water supply & \multirow{3}{*}{$\begin{array}{l}\text { Water } \\
\text { resources } \\
\text { pressure }\end{array}$} & \\
\hline & & Renewable rate & & \\
\hline & & Total water extraction & & Ground water level \\
\hline \multirow{2}{*}{$\begin{array}{l}\mathbf{n} \\
\mathbf{v}\end{array}$} & & $\begin{array}{l}\text { Amount of water resources in } \\
\text { typical, wet and dry years }\end{array}$ & \multirow{4}{*}{$\begin{array}{l}\text { Water } \\
\text { resources state }\end{array}$} & Water depth \\
\hline & & Water reservoirs & & \\
\hline \multirow[b]{3}{*}{$\begin{array}{l}0 \\
\mathbf{n} \\
\mathbf{m}\end{array}$} & & Wetland (beel) & & Natural flushing of wetlands \\
\hline & & Lake area [m2] per $1000 \mathrm{~m}$ grid cell & & \\
\hline & & $\begin{array}{l}\text { Retention area [m2] per } 1000 \mathrm{~m} \text { grid } \\
\text { Percentage of extracted water to } \\
\text { total water resources in typical, wet } \\
\text { and dry years }\end{array}$ & \multirow{2}{*}{$\begin{array}{l}\text { Water } \\
\text { resources } \\
\text { impact }\end{array}$} & Extraction of water \\
\hline \multirow{3}{*}{$\mathbf{n}$} & & Relative water stress index (RWSI) & & Impact on aquatic resources \\
\hline & & Discharge & \multirow{7}{*}{ Water flow } & \\
\hline & & Dominant type of runoff generation & & \\
\hline \multirow[t]{5}{*}{ a } & & Drainage density & & \\
\hline & & Form factor (Horton) & & Physical characteristics of the river \\
\hline & & Water level exceedance & & \\
\hline & & $\begin{array}{l}\text { Monthly discharge ( } 12 \text { mean } \\
\text { monthly discharge values per year } \\
\text { and catchment outlet) }\end{array}$ & & River flow \\
\hline & & Annual runoff pattern & & Runoff \\
\hline
\end{tabular}

\section{Results achieved and deliverables provided}

The choice of the set of indicators is carried out keeping in mind that it should meet the needs and priorities of users (e.g. policy and decision makers, experts, civil society groups) in monitoring processes towards the implementation of IWRM principles in the Upper Danube and Upper Brahmaputra River Basins. The collection of all indicators used by, or relevant to, partners is the first phase planned for the development of a set of integrated indicators within the research phase described here. Therefore, indicator profile forms have been prepared and distributed among the BRAHMATWINN partners to be filled with the information of each indicator they have selected. The template used to define each indicator's profile is divided in three different sections:

1. general information about the indicator: requires providing the main information about the indicator (e.g. name, definition, domain of applicability);

2. rationale for indicator selection: collects synthetic information on the choice of the particular indicator in relation to its usability;

3. data needs: collects information on data needs and data availability for the indicator.
The task of partners was to suggest a way of measuring the list of domains provided in the forms, through indicators. All indicators have been selected because of their policy relevance, with respect to climate change and water resources management, availability of historical time series, data availability over a large part of the UDRB and UBRB and transparency (i.e. they can be easily understood by the policy-makers and the general interested public). The information collected defined a list of indicators, organised according to the domains and sub-domains of reference in the common framework described above, and for further evaluation within the consortium.

In this way the results from the precedent research components (described in Chapter 2, 3 and 4) have been integrated as follows:

1. In Chapter 2 indicators have been developed by the downscaling of Global Climate Models projections.

2. Within Chapter 3 indicators quantifying the assessment and classification of the components of the Natural Environment (NE), such as topography, hydrology and groundwater, snow and glacier cover, permafrost and slope stability, land use and land cover, water quality, eco-hydrology and biodiversity were evaluated.

3. Social, Economic, and Governance indicators have been identified and applied at the local scale in Chapter 4. 
As an example, the Sub-domain Precipitation (Theme: Environment, Domain: Climate) is described by the following indicators:

- Average annual temperature, Extreme temperature indices, Annual mean temperature, Seasonal mean temperature

- Growing season length, Growing season onset

- Hot-day threshold, Cold-day threshold

- Frost days frequency, Longest heat wave

The diversity of each case study area is taken into account at the level of sub-domains through different sets of indicators, which are relevant for each area. Thus, the list of sub-domains constitutes the interface between the quantitative and qualitative data sets. It is at this level that the integration process between quantitative and qualitative information, the latter provided by local actors, takes place. It is difficult to present the whole IIT in a publication such as this one, please refer to Table 2 for an example of how local actors' opinions and BRAHMATWINN researchers' indicators have been matched.

\subsection{Validation}

Three Delphi Rounds were carried out for the development and validation of the Integrated Indicator Table (IIT). The first round was carried out by distributing a template (described above) for the collection of the indicators from each partner. The following two rounds, here described, resulted in the validation of the IIT by the project partners.

Delphi Round 2 consisted in a gap analysis. Confronting the indicators selected by the partners with the concepts elicited from the local actors, a gap analysis has been performed to verify whether the partners have provided indicators suitable to address, quantify, and describe the issues identified by the local actors. When no indicator within the list provided by partners corresponds to an issue or response strategy as expressed by local actors, a gap was identified, which was then filled by the research partners.

This gives information about the appropriateness of the set of indicators proposed to describe problems at the local scale. The consolidation of a list of concepts vs. indicators couples will enable and validate the partners' research outcomes (analysis and modelling) with the opinions provided by the local actors, describing with more detail the needs and issues they have to cope with at the local level. This process allows for the integration of the analysis (both within the human dimension and the natural environment) carried out in the previous phases of the project's implementation in a common framework. The latter will serve to support the decision making process, as a base for the evaluation of different alternative options, carried out later through the application of mDSS.
With Delphi Round 3 the IIT was validated by the BRAHMATWINN partners. It must be said, however, that the IIT must not be thought of a rigid and definitive table, but more of a flexible structure within which indicators can be added or modified according to research needs and new findings.

\section{Contribution to sustainable IWRM}

Indicators have been identified by researchers according to their model outcomes. The indicators selected by researchers have been organised and listed in the IIT. This preliminary list has been integrated, compared and validated with information collected during the Creative System Modelling (CSM) workshops held in the case study areas. In fact, during the CSM workshops participating local actors were asked to share their opinions on the main issues affecting the area considered, with respect to IWRM and in the context of climate change. This process led to the validation of the IIT, which can then be used in several ways to foster IWRM. An example will be discussed in Chapter 8, where criteria derived from indicators will be used to assess relative effectiveness of IWRM responses to cope with flood risk under the impact of climate change.

\section{Conclusions and recommendations}

The creation of the IIT enabled the integration of two processes, one local actor/end-user driven, and the other researcher driven. The framework (Theme, Domain, Subdomain) can thus be seen as the interface between the contributions of local actors and BRAHMATWINN research partners towards the formalization of the problem. Sub-domains represent the level we have decided to deal with in future steps of the project, because they represent the complexity of the system at a level of definition local actors and end-users can deal with.

The IIT was further used in three workshops (Salzburg, October 2008; Kathmandu, November 2008; Kathmandu, November 2009) providing the possibility to local actors to give a final validation of it.

From the results obtained the following recommendation can be made:

1. System analysis and modelling should be integrated into the process of defining integrated indicators, as well as in the workshop discussions with local actors and stakeholders, to enhance their appreciation of the pressing needs. The latter should be addressed when assessing the system dynamics, and when validating their process models to better contribute to decision making for adaptive IWRM and to cope with vulnerabilities.

2. Integrated indicators as analysed in this study should be integrated in the ultimate Integrated Land and Water Resources Management System (ILWRMS) to support decision making on all governance levels, and this is described in more detail in Chapter 9. 
Acknowledgements. We would like to acknowledge the following BRAHMATWINN research partners for contributing to the creation of the Integrated Indicator Table: Geoinformatik Department, Friedrich-Schiller Univerity, Jena (Germany); Department for Geography, Ludwig-Maximilians University, Munich (Germany); Institute for Atmospheric and Environmental Sciences, Goethe University Frankfurt (Germany); Centre for Geoinformatics, University of Salzburg, Salzburg (Austria); GeoData Insitute, University of Southampton (UK); Centre for Water Law, Policy and Science, University of Dundee (UK); Department of Limnology and Hydrobotany, University of Vienna (Austria), Department of Geosciences, University of Oslo (Norway); ICIMOD, Kathmandu (Nepal), Royal University of Bhutan, Thimphu (Bhutan); Indian Institute of Technology Roorkee, Roorkee (India). Last but not least we would also like to acknowledge the contribution of other FEEM researchers who worked in previous phases of the BRAHMATWINN project: Jacopo Crimi, Alessandra Sgobbi and Yaella Depietri.

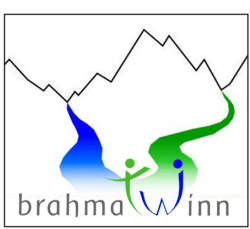

The interdisciplinary BRAHMATWINN EC-project carried out between 2006-2009 by European and Asian research teams in the UDRB and in the UBRB enhanced capacities and supported the implementation of sustainable Integrated Land and Water Resources Management (ILWRM).

\section{References}

DESA/DSD: Indicators of Sustainable Development: Framework and Methodologies, Division for Sustainable Development (DSD), edited by: Department of Economic and Social Affairs (DESA), Background Paper No. 3, Commission on Sustainable Development, Ninth Session, 16-27 April 2001, New York, 2001.

EEA: Environmental Indicators: typology and overview, edited by: European Environment Agency (EEA), Technical report no. 25, Copenhagen, 1999.

EEA: EEA core set of indicators, Guide, edited by: European Environmental Agency (EEA), Technical report, 2005.

Giupponi, C., Sgobbi, A., Mysiak, J., Camera, R., and Fassio, A.: NetSyMoD - An Integrated Approach for Water Resources Management, in: Integrated Water Management, edited by: Meire, P., Coenen, M., Lombardo, C., Robba, M., and Sacile, R., Springer, Netherlands, 69-93, 2008.

OECD: OECD Key Environmental Indicators, edited by: Organisation for Economic Development and Co-Operation (OECD), 2007.

www.unece.org/env/europe/monitoring/IandR_en.html, last access: March 2011.

http://www.euro.who.int/en/what-we-do/data-and-evidence/ environment-and-health-information-system-enhis/ publications, last access: March 2011. 